\title{
MOTIVOS DA NÃO EVIDENCIAÇÃO DE RELATÓRIOS SOCIOAMBIENTAIS DAS COMPANHIAS LISTADAS NO NOVO MERCADO DA B3
}

\author{
Oderlene Vieira de Oliveira \\ Doutora em Administração de Empresas \\ Universidade de Fortaleza \\ Fortaleza - Ceará - Brasil \\ oderlene@hotmail.com \\ Victor Hugo Fernandes de Almeida Ferreira \\ Mestre em Administração de Empresas \\ Universidade de Fortaleza \\ Fortaleza - Ceará - Brasil \\ victorhugofernandes@gmail.com
}

\section{RESUMO}

Embora se reconheça que, nos últimos anos, tenha ocorrido um crescimento na divulgação de relatórios de responsabilidade socioambiental das empresas, admite-se ainda que há um longo caminho a ser percorrido no sentido de que esses relatórios atendam seus usuários, considerando as características de materialidade, consistência, integridade e responsabilidade na informação socioambiental. Nesse contexto, elegeu-se, como objetivo geral, analisar os motivos para não evidenciação dos relatórios socioambientais das empresas listadas no segmento Novo Mercado da B3. Para tanto, foi adotada a abordagem qualitativa, pesquisa do tipo descritiva e documental fazendo uso dos formulários de referência disponibilizados pelas empresas. Como conclusão do estudo, pode-se constatar que as empresas do segmento do Novo Mercado da B3 não estão preocupadas em buscar a tão almejada "diferenciação" mercadológica, pois, do universo de 126 empresas, 56 não evidenciaram os relatórios socioambientais e apenas 42 apontando os motivos da não evidenciação. Sendo eles: (i) não possuem políticas socioambientais (23 empresas); (ii) precisam melhorar os seus processos internos (7 empresas); (iii) fatores organizacionais e valores (7 empresas); (iv) custos (3 empresas); e (v) Legislação e Regulamentação Ambiental (2 empresas). Como contribuição acadêmica apresentou-se um novo motivo para não divulgação dos relatórios de sustentabilidade - não possuir políticas socioambientais.

Palavras-chave: Evidenciação ambiental. Governança corporativa. Responsabilidade social corporativa.

\section{REASONS FOR NON-DISCLOSURE OF REPORTS ON SOCIAL AND ENVIRONMENTAL RESPONSIBILITY OF COMPANIES LISTED ON THE NEW B3 STOCK EXCHANGE}

\begin{abstract}
Although there has been an increase in the disclosure of reports on social and environmental responsibility of companies, there are big steps that must be taken regarding these reports which should meet the demands of stakeholders, considering materiality, consistency, integrity and responsibility aspects in disclosure social and environmental information. Thus, this article aims to analyze the reasons for non-disclosure of social and environmental reports of the companies listed on the new B3 stock exchange. This study uses a qualitative approach and it is a descriptive and documentary research. The results show that the companies listed on the new B3 stock exchange are not concerned with differentiation on the marketplace, since 56 out of 126 companies do not disclosure social and environmental reports, and 42 point out the reasons of the nondisclosure, which are: (i) they do not have social and environmental internal policies (23 companies); (ii) they need to improve internal processes ( 7 companies); (iii) organizational aspects and values ( 7 companies); (iv) costs (3 companies); and Environmental Legislation and Regulations (2 companies). As a scholarly contribution, a new reason was identified for non-disclosure of sustainability reports - not having socioenvironmental policies.
\end{abstract}

Key words: Corporate governance. Corporate social responsibility. Environmental disclosure. 


\section{INTRODUÇÃO}

Com a sociedade moderna mundial cada vez mais preocupada com a sustentabilidade, o disclosure socioambiental tornou-se uma atividade fundamental na competitividade e no desempenho das empresas (Baumgartner, 2014). Nesse sentido, Cormier e Magnan (2013) comentam que o disclosure socioambiental é relevante economicamente para o mercado financeiro e o afeta de maneira direta ou indireta. Também é essencial, para os analistas e investidores financeiros, que se beneficiam com uma maior transparência. Assim, isso se traduz num melhor relacionamento das empresas com os stakeholders (ILG, 2007). Contudo, há empresas que possuem apenas um engajamento socioambiental parcial em seus relatórios (Rodrigue, 2014).

Pesquisas, a exemplo da realizada por Luo (2006), evidenciam que empresas que possuem na sua gestão práticas de governança corporativa têm apresentado um bom desempenho na responsabilidade social corporativa. Desempenho este presente principalmente nas companhias de capital aberto, as quais contemplam cada vez mais critérios de sustentabilidade (Lane, 2003; Tirole, 2001) como orientação para os stakeholders (Schmidt \& Tyrell, 1997).

Uma parcela significante do sucesso de uma organização é proveniente da legitimidade de suas atividades perante os seus stakeholders (Freeman, 1984) e o disclosure socioambiental é uma forma de buscar essa legitimidade. Apesar da publicação dos relatórios socioambientais no Brasil não ser obrigatória, existem várias recomendações para a divulgação ambiental, como o Parecer de Orientação n.15/87 da CVM, a Norma e Procedimento de Auditoria n.11 do Instituto dos Auditores Independentes do Brasil, e a Resolução n.1.003/04 do Conselho Federal de Contabilidade que aprovou a Norma Brasileira de Contabilidade Técnica n.15 (Rover et al., 2008). Também naquele sentido, a Brasil, Bolsa e Balcão (B3, antiga BM\&FBovespa), em dezembro de 2011, passou a recomendar que a partir de 2012 as empresas listadas deveriam indicar no formulário de referência (item 7.8) se publicavam relatório de sustentabilidade ou similar e onde estaria disponível. E em caso negativo, deveriam explicar o motivo porque não o faziam; adicionalmente, a B3 sinalizava que as empresas deveriam utilizar o relatório "Relate ou Explique" para exporem o motivo da não evidenciação dos relatórios de sustentabilidade. Em linha com essa determinação e reforçando-a, a Comissão de Valores Monetários (CVM) criou no sistema de Informações Periódicas Eventuais (IPE), em dezembro de 2011, uma nova categoria denominada "relatórios de sustentabilidade" na qual a empresa deveria arquivar o seu relatório (BM\&FBovespa, 2016). Frente a esse contexto, elaborou-se a seguinte questão de pesquisa: Quais os motivos da não evidenciação de relatórios socioambientais pelas companhias listadas no segmento Novo Mercado da B3? Nesse sentido, foi definido como objetivo geral analisar os motivos para não evidenciação dos relatórios socioambientais das empresas listadas no segmento Novo Mercado da B3. Para tanto foram definidos os seguintes objetivos específicos: 1) identificar as companhias listadas no segmento Novo Mercado da B3 que não publicam o relatório de sustentabilidade; 2) identificar os motivos da não divulgação dos relatórios de sustentabilidade; e 3) averiguar no website das companhias listadas no segmento Novo Mercado da B3 que não publicaram o relatório de sustentabilidade se foi evidenciada alguma política socioambiental.

Embora sejam frequentes estudos voltados a evidenciação ambiental, socioambiental e a divulgação voluntária, estes estudos ainda estão fortemente relacionados a temas que envolvem os determinantes da divulgação, relação entre performance versus disclosure ambiental e impactos relacionados ao disclosure quanto à reação do mercado (De Moraes et al., 2017). Assim, observouse que ainda são poucos os estudos que buscam identificar os motivos da não evidenciação por parte das empresas e uma carência ainda maior de estudos que foquem na análise dos motivos da não evidenciação (Hendriksen \& Van Breda, 1999; Braga, Oliveira, \& Salotti, 2009; Rover et al., 2012; Degenhart et al., 2016).

A relevância desta pesquisa se dá pelo fato de que a comunicação de caráter socioambiental tem causado interesse não só dos stakeholders, que cada vez mais exigem informações dessa natureza para tomada de decisões, mas de pesquisadores, em particular na linha de evidenciação de 
informações (Monteiro \& Ferreira, 2007). Adicionalmente, cabe destacar que os temas governança corporativa e a responsabilidade social corporativa vem sendo estudados, na maioria das vezes, de forma isolada, mesmo estudos tendo apontado a relação de complementaridade existente entre elas (Beltratti, 2005).

\section{REFERENCIAL TEÓRICO}

Esta seção é composta de duas subseções. A primeira aborda a Sinergia entre RSC e Governança Corporativa, pois ambos os conceitos são complementares e devem andar juntos para uma maior valorização e transparência socioambiental da empresa. E na segunda subseção o foco é nos motivos para não evidenciação dos relatórios socioambientais.

\subsection{Responsabilidade social corporativa e governança corporativa}

Apesar de várias décadas de pesquisa (Aguilera et al., 2006; Aras \& Crowther, 2008; Jamali \& Neville, 2011; Knox \& Maklan, 2004), a relação entre responsabilidade social corporativa (RSE) e governança corporativa ainda não está clara (Arora \& Dharwadkar, 2011; Harjoto \& Jô, 2011). Para Elkington (2006), por exemplo, a fusão entre responsabilidade social corporativa e governança corporativa, se dá a partir da ideia do 3BL (três pilares da sustentabilidade. Sendo que esta sinergia é abordada de forma mais clara quando a governança corporativa é considerada de modo mais abrangente, ou seja, não apenas a transparência, honestidade e a prestação de contas aos acionistas, mas também de responsabilidade para com todos os stakeholders (Dunlop, 1998; Jamali, Safieddine, \& Rabbath, 2008). Já para Sacconi (2012) a responsabilidade social seria um modelo de governança corporativa. E Beltratti (2005) considera a RSC e governança corporativa como conceitos complementares, podendo se reforçar mutuamente. O autor comenta que existe uma relação positiva entre ambas e a possibilidade de a governança distinguir as organizações não apenas pelos resultados contábeis, mas também pela sustentabilidade.

Apesar da falta de clareza, a literatura acadêmica destaca que a RSE e a governança corporativa estão fortemente e intricadamente conectadas, observando que a literatura anterior não conseguiu captar a natureza e a essência desse relacionamento (Jamali et al., 2008; Jo \& Harjoto, 2012). Também estudiosos da RSC enfatizam a necessidade de manter internamente os mais altos padrões de governança, particularmente nas discussões sobre a dimensão interna da RSC (Perrini, Pogutz, \& Tencati, 2006). Tanto a governança corporativa quanto a RSC exigem que as empresas assumam suas responsabilidades éticas e morais em relação aos stakeholders. Esse ato de responsabilização é crucial para que uma empresa obtenha e retenha a confiança de seus investidores financeiros e outras partes interessadas (Page, 2005).

Ambos os conceitos extraem o vigor das mesmas fontes que são: transparência, responsabilidade e honestidade (Van Den Berghe \& Louche, 2005). As boas iniciativas da governança corporativa e RSC estão avançando gradualmente de uma variante filantrópica do capitalismo corporativo para estratégias autênticas destinadas a recuperar a confiança dos clientes e da sociedade em geral. Enquanto a governança corporativa implica "ser responsabilizado", a RSC significa "levar em conta" e ambos os mecanismos são cada vez mais utilizados pelas empresas para regular suas operações (Marsiglia \& Falautano, 2005).

No âmbito da teoria da legitimidade, a governança corporativa e a RSC são conceitos intrinsecamente relacionados que definem a interação entre uma organização e seu ambiente sociopolítico interno e externo, sendo cada vez mais consideradas como pré-requisitos fundamentais complementares para o crescimento sustentável em um ambiente corporativo cada vez mais globalizado (Van Den Berghe \& Louche, 2005). A RSC pode ser vista como uma extensão da governança corporativa eficaz por parte da empresa, assegurando a sustentabilidade do negócio pelo uso de práticas que levem a responsabilização e transparência visíveis a toda a sociedade (Jô \& Harjoto, 2012).

Revista de Gestão Social e Ambiental - RGSA, São Paulo, v. 12, n. 3, p. 58-76, set./dez. 2018. 
Khan, Muttakin e Siddiqui (2013), ressaltam que a pesquisa sobre a relação destes temas é escassa e tem sido predominantemente efetuada sobre as relações entre a responsabilidade social e o desempenho financeiro com algumas associações positivas e em relação com a governança corporativa como a independência dos conselhos de administração, a liderança organizacional e as participações institucionais.

Dentre as pesquisas que estudam a relação entre RSC e governança corporativa, vale destacar a realizada por Jamali et al. (2008), em que fazem uma revisão de três modelos que postulam uma relação entre a governança corporativa e a responsabilidade social. Estes modelos apresentam três propostas a serem desenvolvidas: (i) a governança corporativa como um pilar da responsabilidade social (Hancock, 2005); (ii) a responsabilidade social como uma dimensão da governança corporativa (Ho, 2005); e (iii) a governança corporativa e a responsabilidade social como parte do continuum (Bhimani \& Soonawalla, 2005).

O modelo da governança corporativa como um pilar da responsabilidade social corporativa pressupõe a existência de um modelo efetivo com uma base sólida para, nesse suporte, se desenvolverem as iniciativas de responsabilidade social. O modelo de Jamali, Safieddine e Rabbath (2008) considera que são necessários quatro pilares estratégicos para a construção de um sistema de responsabilidade social que, considerados em conjunto, ajudam a mensurar o valor real de uma empresa e a sua capacidade de criação de valor futuro. Estes pilares são: (i) a governança corporativa; (ii) o capital humano; (iii) o "capital" dos stakeholders; e (iv) o ambiente externo.

A governança corporativa é considerada como um dos blocos básicos para a construção e existência da responsabilidade social, visto que fornece à empresa a devida orientação e autorregulação, como potência uma maior abertura da cultura organizativa para a inovação, agilidade e flexibilidade para responder às novas condições do mercado (Jamali et al., 2008).

Já o modelo de Ho (2005) considera a responsabilidade social como uma dimensão da governança corporativa. A governança corporativa é composta por dimensões como: (i) a administração; (ii) a liderança estratégica; (iii) a estrutura do Conselho de Administração; (iv) a estrutura de capitais e as relações com o mercado; e (iv) as responsabilidades sociais. Ho (2005) propõe, avaliar a governança corporativa de forma mais holística, considerando uma série de atributos relevantes, incluindo a RSC. A boa governança também implica assegurar que as empresas são geridas de forma socialmente responsável e que deve haver uma base claramente ética para as empresas que cumprem as normas da sociedade em que estão operando. Em outras palavras, de acordo com esse modelo, ser responsável externamente com a sociedade em geral e internamente com os funcionários deve ser incorporado em formulações e estruturas de governança corporativa.

O estudo de Ho (2005) fornece evidências de que os maiores compromissos com a RSC estão forte e positivamente relacionados com as qualificações e os termos dos diretores, conselhos que exercem fortes funções de administração e liderança estratégica e a gestão das pressões do mercado de capitais as características de uma boa governança corporativa.

\subsection{Motivos de não evidenciação de relatórios socioambientais}

Para Perron (2005), as barreiras são elementos que impedem a adoção de iniciativas socioambientais nas organizações e são classificadas em quatro categorias: (i) barreiras técnicas: são barreiras que dificultam ou impossibilitam a ascensão e a acessibilidade do conhecimento, por exemplo, a ausência de novas tecnologias, experiências ou materiais; (ii) barreiras de recurso: ausência de algum tipo de recurso para a implantação da gestão socioambiental, por exemplo, recursos humanos e recursos financeiros escassos; (iii) barreiras de informação: dificuldade de comunicação e impede a acessibilidade da informação, por exemplo, falta de conhecimento da legislação ambiental e o impacto ambiental das operações da empresa e (iv) barreiras perceptivas ou atitudinais: falta de percepção, de atitudes e comportamentais da alta gerência para com as questões ambientais, por exemplo, resistência da gerência a mudanças. 
As empresas se deparam com fatores externos e internos à organização que assumem o aspecto barreiras para a adoção da evidenciação. Ao selecionar alguns artigos sobre o tema na base de dados Google Acadêmico, Spell e Science Direct por meio de uma revisão da literatura foi possível agrupá-los.

$\mathrm{Na}$ Figura 1 é apresentado uma síntese das barreiras externas para a evidenciação de relatórios socioambientais.

\begin{tabular}{|c|c|c|}
\hline $\begin{array}{c}\text { Fatores } \\
\text { externos }\end{array}$ & Definição & Autores \\
\hline Consumidores & $\begin{array}{l}\text { Desejam serviços e produtos que agradam cada vez mais } \\
\text { os seus anseios e necessidades, portanto provocando } \\
\text { pressões nas organizações exercendo influência sobre o } \\
\text { mercado onde a organização atua. }\end{array}$ & $\begin{array}{l}\text { Luthra et al. (2011); Simpson } \\
\text { (2012). }\end{array}$ \\
\hline $\begin{array}{l}\text { Legislação e } \\
\text { regulamentação } \\
\text { governamental }\end{array}$ & $\begin{array}{l}\text { Relaciona-se aos órgãos regulamentadores, que produzem } \\
\text { normas de comportamento e leis para a organização, } \\
\text { obrigando a empresa à adoção de práticas por parte das } \\
\text { mesmas. }\end{array}$ & $\begin{array}{l}\text { Bjorklund (2011);Pajunen et al. } \\
\text { (2012);Tsoulfas e Pappis } \\
\text { (2008); Luthra et al. } \\
\text { (2011);Walker, Sisto e Mcbain } \\
\text { (2008);Giunipero, Hooker e } \\
\text { Denslow (2012). }\end{array}$ \\
\hline Fornecedores & $\begin{array}{l}\text { Fabricantes de peças, componentes e transformadores de } \\
\text { matéria-prima. }\end{array}$ & $\begin{array}{l}\text { Luthra et al. (2011);Bjorklund } \\
\text { (2011);Mathiyazhaganet al. } \\
\text { (2013). }\end{array}$ \\
\hline Concorrência & $\begin{array}{l}\text { Incita as organizações a manterem-se competitivas no } \\
\text { mercado e intensamente produtivas. }\end{array}$ & $\begin{array}{l}\text { Luthra et al. (2011); } \\
\text { Bjorklund (2011). }\end{array}$ \\
\hline Tecnologia & $\begin{array}{l}\text { É uma forma de conhecimento que a organização adquiri } \\
\text { com o objetivo de obter maiores habilidades para inserir } \\
\text { essa inovação. }\end{array}$ & $\begin{array}{l}\text { Luthra et al. (2011); Yongan e } \\
\text { Menghan (2011). }\end{array}$ \\
\hline $\begin{array}{l}\text { Sociedade e } \\
\text { imagem } \\
\text { corporativa }\end{array}$ & $\begin{array}{l}\text { Os grupos de interesse são influenciados e sensíveis por } \\
\text { qualquer mudança de atitude ou comportamento das } \\
\text { organizações, a imagem da organização influencia nas } \\
\text { escolhas dos clientes finais. }\end{array}$ & Walker, Sisto e Mcbain (2008). \\
\hline
\end{tabular}

Figura 1. Motivos externos para não evidenciação de relatórios socioambientais

Fonte: Elaborado pelos autores (2017)

A falta de informação e consciência dos consumidores sobre o desempenho e a vantagem dos produtos faz que eles escolham produtos de péssimo desempenho, mas com custos mais baixos (Luthra et al., 2011). E se a organização entender que para sobreviver tem que abaixar a qualidade dos seus produtos e ceder a essas pressões dos clientes, podem levar as empresas a despejar ilegalmente seus resíduos ou procurar opções de tratamento com um custo mais baixo (Simpson, 2012).

A legislação e a regulamentação governamental atuam como motivos a não evidenciação quando há ausência de informação e as diretrizes das autoridades não são claras (Bjorklund, 2011), considerações ambientais na cadeia de suprimentos (Tsoulfas \& Pappis, 2008) e o bloqueio do uso de várias substâncias empregadas na concepção dos produtos (Pajunen et al., 2012). A ausência também de uma regulamentação adequada pode se tornar um fator inibidor à adoção dos relatórios de sustentabilidade, principalmente quando se tratam de empresas reativas (Luthra et al., 2011; Giunipero, Hooker, \& Denslow, 2012). A falta de conscientização e das pressões da legislação e regulamentação fazem com quem as empresas adotem essas evidenciações de forma voluntária (Zhu et al., 2011). O governo, não adotando ações que possam proporcionar condições adequadas para que as empresas possam implantar os relatórios de sustentabilidade por meio de apoio financeiro e técnico, além de alavancar investimentos na melhoria do ambiente industrial e aumentar o alcance do conhecimento sobre Gestão Ambiental forma uma barreira (Wu, Ding, \& Chen, 2012).

Apesar de não serem os responsáveis diretos, a falta de competência, inclusive a falta de conhecimento, em relação aos serviços prestados, seja de fornecimento ou entrega de materiais, 
gera uma barreira à implantação da Gestão Ambiental e Social (Bjorklund, 2011) principalmente quando os fornecedores são resistentes a mudanças (Luthra et al., 2011; Mathiyazhagan et al., 2013).

Quando as empresas optam pelas práticas de iniciativas ambientais, elas desejam conquistar vantagem competitiva (Giunipero et al., 2012) e a conexão estabelecida entre os concorrentes é de vital importância para as questões ambientais (Bjorklund, 2011). Uma vez que as prioridades para os investimentos são mais complexas (Luthra et al., 2011) e são um fator de limitação ao escopo ambiental (Bjorklund, 2011).

Sendo uma forma de conhecimento, a empresa que adquirir tecnologia terá maiores habilidades para inserir essa inovação. Porém, está se torna uma barreira quando ocorre resistência em incorporá-la, pois isso afeta a cultura organizacional, as estratégias de operações, logística, objetivas e a forma de gerenciamento (Luthra et al., 2011). Também é uma barreira a falta de conhecimento e de proteção para a inovação tecnológica (Yongan \& Menghan, 2011).

A marca e a reputação da empresa são assuntos muito comentados atualmente, pois os clientes são suscetíveis a atitudes e aos comportamentos das organizações que alcançam uma imagem positiva no mercado, pois os clientes lembram-se mais dela e, em decorrência, compram os seus produtos (Tate, Dooley, \& Ellram, 2011).

Na Figura 2 apresenta-se uma síntese das barreiras internas para a evidenciação de relatórios socioambientais.

\begin{tabular}{|c|c|c|}
\hline $\begin{array}{l}\text { Fatores } \\
\text { internos }\end{array}$ & Definição & Autores \\
\hline $\begin{array}{l}\text { Fatores } \\
\text { organizacionais } \\
\text { e valores }\end{array}$ & $\begin{array}{l}\text { É o apoio e o comprometimento dos funcionários e } \\
\text { dos membros da alta cúpula administrativa. Engloba } \\
\text { questões culturais, gestão de conhecimento e } \\
\text { atendimento de parâmetros objetivos. }\end{array}$ & $\begin{array}{l}\text { Luthra et al. (2011); Walker, Sisto e } \\
\text { Mcbain (2008); Ageron, Gunasekaran } \\
\text { e Spalanzani (2012). }\end{array}$ \\
\hline Custos & $\begin{array}{l}\text { Termo financeiro que proporciona ou inibe a } \\
\text { execução de melhorias e mudanças nos produtos e } \\
\text { processos organizacionais. }\end{array}$ & $\begin{array}{l}\text { Pajunen et al. (2012); Walker, Sisto e } \\
\text { Mcbain (2008); Luthra et al. (2011); } \\
\text { Muludi et al. (2012) } \\
\text { Zhang, Bi, Liu (2009); Giunipero, } \\
\text { Hooper e Denslow (2012). }\end{array}$ \\
\hline $\begin{array}{l}\text { Recursos } \\
\text { humanos }\end{array}$ & Relacionam-se ao capital humano da empresa. & $\begin{array}{l}\text { Luthra et al. (2011);Wolfslehner e } \\
\text { Vacik (2008). }\end{array}$ \\
\hline $\begin{array}{l}\text { Disponibilidade } \\
\text { de recursos }\end{array}$ & $\begin{array}{l}\text { Relacionam-se à disponibilidade de capacidade de } \\
\text { processos organizacionais, ativos, informações e } \\
\text { conhecimentos, tributos, tempo e recursos } \\
\text { financeiros. }\end{array}$ & $\begin{array}{l}\text { Adriana (2009); Zhu e Geng } \\
\text { (2013);Luthra et al. (2011). }\end{array}$ \\
\hline $\begin{array}{l}\text { Processos de } \\
\text { melhoria } \\
\text { continua }\end{array}$ & $\begin{array}{l}\text { Relacionam-se a busca pela melhoria constante da } \\
\text { qualidade dos produtos, processos e serviços. A } \\
\text { certificação ISO } 14001 \text { ajusta as organizações aos } \\
\text { padrões ambientais auditados. }\end{array}$ & De Oliveira e Serrab (2010). \\
\hline
\end{tabular}

Figura 2. Motivos internos para não evidenciação de relatórios socioambientais

Fonte: Elaborado pelos autores (2017)

Luthra et al. (2011) e Walker, Sisto e McBain (2008) concordam que os fatores organizacionais funcionam como barreiras. A inexistência do apoio e do comprometimento dos membros da alta cúpula administrativa por meio da solidarização das informações (Youn et al., 2013), a falta de incentivo que os funcionários adotem e desenvolvam as práticas de gestão ambiental (Caniato et al., 2012; Chiou et al., 2011) e social (Crespin-Mazet \& Dontenwill, 2012; Giunipero et al., 2012) com auxílio de valores organizacionais e políticos, funcionam como barreiras para a não evidenciação. Fatores organizacionais são evidenciados como barreiras quando há teimosia a modificações pelos funcionários, alta gerência, tipos de negócio, questões financeiras, sistemas de capacidade, localização, formato da rede de fornecimento, cultura organizacional, desempenho de objetivos, custos, gestão do conhecimento (Ageron, Gunasekaran, \& Spalanzani, 
2012), falta de alinhamento com os objetivos de longo e curto prazo e pela falta de unanimidade no nível estratégico (Giunipero et al., 2012).

Os custos são um dos fatores mais importantes e atuam como barreiras (Pajunen et al., 2012), principalmente quando impossibilitam o processo de implantação das práticas de gestão ambiental em decorrência dos altos investimentos iniciais (Walker et al., 2008). Os custos são um dos primeiros parâmetros de desempenho, classificados como custo de transação e diretos. Quando existe custo com a contratação de profissionais altamente qualificados, adoção de tecnologias inovadoras e com treinamento de pessoal, eles são considerados como barreiras (Luthra et al., 2011). Os custos são considerados barreiras (Zhang, Bi, \& Liu, 2009; Muduli et al., 2013) quando a organização assume o projeto de implementar práticas "verdes", já que o valor disponibilizado para esse fim é alto, os produtos verdes têm a tendência a serem mais caros e também são elevados os custos da sua produção, pois precisam de um custo específico para as mudanças e investimentos em máquinas com maior desempenho energético (Giunipero et al., 2012).

Os funcionários atuam como barreiras quando a organização tem o desejo de introduzir inovações e, em razão das modificações que acontecem internamente, são produzidas resistências (Luthra et al., 2011), quando ao impactar o ambiente modificam o seu estado natural (Wolfslehner \& Vacik, 2008). A falta ou a escassez de recursos é uma barreira para à adoção de práticas sustentáveis (Adriana, 2009; Zhu \& Geng, 2013). É imprescindível tanto investimento em recursos humanos como financeiro, porém nem todas as organizações têm capital livre ou não desejam investir nessas práticas sustentáveis (Luthra et al., 2011).

A busca pela melhoria contínua na qualidade dos produtos e serviços é obtida por meio da certificação ISO 14001(Arimura, Darnall, \& Katayama, 2011; Zhu \& Geng, 2013). A certificação ajuda nos processos e os planejamentos da organização auxiliam na redução do consumo de energia, na reciclagem e reutilização de materiais e na melhoria dos padrões de sustentabilidade (Giunipero et al., 2012). Porém, é uma grande barreira à implantação quando a empresa passa por problemas de recursos, quando necessitam contratar profissionais e serviços especializados, a inexistência de poucas empresas confiáveis à destinação dos resíduos e o custo elevado no seu descarte (De Oliveira e Serrab, 2010).

A seguir, apresenta-se a metodologia que guiou os passos dos pesquisadores no decorrer da elaboração da pesquisa.

\section{METODOLOGIA}

Neste estudo, adotou-se a abordagem qualitativa (Strauss \& Corbin, 2008). Quanto aos fins, trata-se de uma pesquisa descritiva utilizando fontes secundárias (Collis \& Hussey, 2005). Quanto aos meios, trata-se de uma pesquisa documental (Patton, 2012). Foi estabelecido como populaçãoalvo as empresas listadas no segmento Novo Mercado de governança corporativa da Brasil, Bolsa e Balcão (B3), antiga BM\&FBovespa, um total de 126 companhias de vários setores econômicos, conforme exposto a seguir e sintetizada na Tabela 1. A seleção do segmento Novo Mercado se deve ao fato de este ser o segmento com maior nível de governança corporativa da B3 e, consequentemente, o segmento com maior nível de evidenciação de informações.

Tabela 1: Companhias listadas no segmento novo mercado

\begin{tabular}{cccc}
\hline Setor econômico & Total & Setor econômico & Total \\
\hline Utilidade Pública & 09 & Petróleo, Gás e Biocombustíveis & 07 \\
Consumo Não Cíclico & 13 & Tecnologia da Informação & 04 \\
Materiais Básicos & 10 & Financeiro e Outros & 17 \\
Saúde & 07 & Consumo Cíclico & 40 \\
Bens Industriais & 20 & Total & $\mathbf{1 2 6}$ \\
\hline
\end{tabular}

Fonte: Elaborado pelos autores (2017)

Revista de Gestão Social e Ambiental - RGSA, São Paulo, v. 12, n. 3, p. 58-76, set./dez. 2018. 
No processo de coleta de dados, utilizou-se de documentos. Assim, no que se refere à investigação documental, foram pesquisados: a) relatórios "relate ou explique" para relatórios de sustentabilidade ou integrado do ano de 2015 ; b) formulários de referência; e c) relatórios de sustentabilidade ou integrado. A escolha do ano de 2015 se deve ao fato de que em revisão promovida pela Comissão de Valores Mobiliários (CVM) em seu formulário de referência, tornou o item 7.8 exclusivo para informações socioambientais a partir de 2016. Sendo assim, a B3 julgou não ser mais necessário recomendar a divulgação do formulário de referência, e o compromisso das companhias passou a partir de 2016 a ser diretamente com a CVM (BM\&FBovespa, 2016). Portanto, os últimos dados disponíveis referem-se ao ano de 2015.

Em relação a coleta dos dados, procedeu-se inicialmente uma busca no site da B3, tendo em vista que é o local onde encontram-se os formulários de referência, com o objetivo de verificar quais empresas evidenciaram ou não os formulários. Ainda no site da B3, buscou-se os relatórios relate ou explique para identificar os motivos da não evidenciação pelas empresas que não publicaram o formulário de referência. Adicionalmente, para as empresas que não publicaram o formulário de referência foram realizadas pesquisas na home page das empresas para verificar se havia alguma evidência de relatórios socioambientais. O período de coleta de dados compreendeu os meses de setembro de 2016 a fevereiro de 2017.

Para analisar os dados, utilizou-se de análise de conteúdo (Bardin, 2011). A técnica de análise de conteúdo possibilitou a identificação e análise das informações investigadas nos relatórios das companhias. Seguiram-se três etapas para a condução da análise de conteúdo: 1) préanálise - foram acessados os websites das companhias, e examinados com o propósito de identificação do link relacionado com as questões socioambientais das suas atividades. A seguir, os relatórios anuais e os relatórios específicos disponíveis de cada companhia foram baixados e organizados para codificação e posterior análise; 2) Exploração do material -consistiu na análise sistemática dos relatórios com o propósito de identificar ou não as categorias pré-estabelecidas (expostas na Figura 3), controle da frequência da aparição dos elementos investigados nas mensagens, medido em percentual, para posteriores interpretações dos achados. E nessa etapa, foi utilizado o Atlas/TI; e 3) Tratamento dos resultados - procedeu-se à interpretação dos dados.

\begin{tabular}{|c|c|c|}
\hline & Fatores externos & \\
\hline Categorias & Definição & Autores \\
\hline Consumidores & $\begin{array}{l}\text { Desejam serviços e produtos que agradam cada vez } \\
\text { mais os seus anseios e necessidades, portanto } \\
\text { provocando pressões nas organizações exercendo } \\
\text { influência sobre o mercado onde a organização atua. }\end{array}$ & $\begin{array}{l}\text { L Luthra et al. (2011); Simpson } \\
\text { (2012). }\end{array}$ \\
\hline $\begin{array}{l}\text { Legislação e } \\
\text { regulamentação } \\
\text { governamental }\end{array}$ & $\begin{array}{l}\text { Relaciona-se aos órgãos regulamentadores, que } \\
\text { produzem normas de comportamento e leis para a } \\
\text { organização, obrigando a empresa à adoção de } \\
\text { práticas por parte das mesmas. }\end{array}$ & $\begin{array}{l}\text { Bjorklund (2011); Pajunen et al. } \\
\text { (2012);Tsoulfas e Pappis } \\
\text { (2008);Luthra et al. (2011);Walker, } \\
\text { Sisto e Mcbain (2008);Giunipero, } \\
\text { Hooker e Denslow (2012). }\end{array}$ \\
\hline Fornecedores & $\begin{array}{l}\text { Fabricantes de peças, componentes e } \\
\text { transformadores de matéria-prima. }\end{array}$ & $\begin{array}{l}\text { Luthra et al. (2011);Bjorklund } \\
\text { (2011);Mathiyazhagan et al. (2013). }\end{array}$ \\
\hline Concorrência & $\begin{array}{l}\text { Incita as organizações a manterem-se competitivas } \\
\text { no mercado e intensamente produtivas. }\end{array}$ & $\begin{array}{l}\text { Luthra et al. (2011); } \\
\text { Bjorklund (2011). }\end{array}$ \\
\hline Tecnologia & $\begin{array}{l}\text { É uma forma de conhecimento que a organização } \\
\text { adquire com o objetivo de obter maiores habilidades } \\
\text { para inserir essa inovação. }\end{array}$ & $\begin{array}{l}\text { Luthra et al. (2011); Yongan e } \\
\text { Menghan (2011). }\end{array}$ \\
\hline $\begin{array}{l}\text { Sociedade e } \\
\text { imagem } \\
\text { corporativa }\end{array}$ & $\begin{array}{l}\text { Os grupos de interesse são influenciados e sensíveis } \\
\text { por qualquer mudança de atitude ou comportamento } \\
\text { das organizações, a imagem da organização } \\
\text { influencia nas escolhas dos clientes finais. }\end{array}$ & Walker, Sisto e Mabain (2008). \\
\hline
\end{tabular}




\begin{tabular}{|l|l|l|}
\hline Fatores internos & \multicolumn{3}{|l|}{$\begin{array}{l}\text { Fatores } \\
\text { organizacionais } \\
\text { e valores }\end{array}$} & $\begin{array}{l}\text { É o apoio e o comprometimento dos funcionários e } \\
\text { dos membros da alta cúpula administrativa. Engloba } \\
\text { questões culturais, gestão de conhecimento e } \\
\text { atendimento de parâmetros objetivos. }\end{array}$ & $\begin{array}{l}\text { Luthra et al. (2011); Walker, Sisto e } \\
\text { Mcbain (2008); Ageron, Gunasekaran } \\
\text { e Spalanzani (2012). }\end{array}$ \\
\hline Custos & $\begin{array}{l}\text { Termo financeiro que proporciona ou inibe a } \\
\text { execução de melhorias e mudanças nos produtos e } \\
\text { processos organizacionais. }\end{array}$ & $\begin{array}{l}\text { Pajunen et al. (2012); Walker, Sisto e } \\
\text { Mcbain (2008); Luthra et al. (2011); } \\
\text { Muludi et al. (2012) } \\
\text { Zhang, Bi, Liu (2009); Giunipero, } \\
\text { Hooper e Denslow (2012). }\end{array}$ \\
\hline $\begin{array}{l}\text { Recursos } \\
\text { humanos }\end{array}$ & $\begin{array}{l}\text { Relacionam-se ao capital humano da empresa. } \\
\text { Vacik (2008). }\end{array}$ \\
\hline $\begin{array}{l}\text { Disponibilidade } \\
\text { de recursos }\end{array}$ & $\begin{array}{l}\text { Relacionam-se à disponibilidade de capacidade de } \\
\text { processos organizacionais, ativos, informações e } \\
\text { conhecimentos, tributos, tempo e recursos } \\
\text { financeiros. }\end{array}$ & $\begin{array}{l}\text { Adriana (2009); Zhu e Geng } \\
\text { (2013);Luthra et al. (2011). }\end{array}$ \\
\hline $\begin{array}{l}\text { Processos de } \\
\text { melhoria } \\
\text { continua }\end{array}$ & $\begin{array}{l}\text { Relacionam-se a busca pela melhoria constante da } \\
\text { qualidade dos produtos, processos e serviços. A } \\
\text { certificação ISO 14001 ajusta as organizações aos } \\
\text { padrões ambientais auditados. }\end{array}$ & De Oliveira e Serrab (2010). \\
\hline
\end{tabular}

Figura 3: Categorias de análise

Fonte: Elaborado pelos autores (2017)

Para a definição das categorias, foi preciso reunir as principais conclusões teóricas relevantes relacionadas ao propósito da pesquisa que é descobrir os motivos para não evidenciação de informações de cunho socioambiental das companhias listadas no Novo Mercado da B3. Entretanto, os conceitos-chaves (categorias) emergiram da teoria e não dos dados.

\section{RESULTADOS E DISCUSSÃO}

Nesta seção, apresenta-se inicialmente um panorama da divulgação de informações socioambientais das empresas por setor econômico; e, posteriormente, centra-se na discussão dos motivos da não divulgação dos relatórios de sustentabilidade.

\subsection{Setores econômicos que divulgam ou não relatórios de sustentabilidade}

$\mathrm{Na}$ Tabela 2, apresenta-se o total das empresas por setor econômico que divulgam informações e das que não divulgam informações socioambientais em relatórios de sustentabilidade. Observa-se que o setor econômico que mais evidenciou o relatório de sustentabilidade foi o de utilidade pública, em que oito das nove empresas listadas divulgaram o relatório de sustentabilidade; e o setor que menos evidenciou o relatório foi o de consumo cíclico, em que apenas 13 das 40 empresas divulgaram o relatório de sustentabilidade.

Tabela 2: Divulgação de Relatórios Socioambientais

\begin{tabular}{cccc}
\hline SETOR ECONÔMICO & FREQUÊNCIA & DIVULGOU & NÃO DIVULGOU \\
\hline Consumo cíclico & 40 & 13 & 27 \\
Bens industriais & 20 & 13 & 7 \\
Financeiro e outros & 17 & 6 & 11 \\
Consumo não cíclico & 13 & 11 & 2 \\
Utilidade pública & 9 & 8 & 1 \\
Materiais básicos & 9 & 8 & 1 \\
Petróleo, gás e biocombustíveis. & 7 & 4 & 3 \\
Saúde & 7 & 5 & 2 \\
Tecnologia da informação & 4 & 2 & 2 \\
\hline TOTAL & $\mathbf{1 2 6}$ & $\mathbf{7 0}$ & $\mathbf{5 6}$
\end{tabular}

Fonte: Elaborado pelos autores (2017) 
Ainda observando a Tabela 2 e atentando para o total de empresas que não divulgou o relatório de sustentabilidade, vê-se que o setor que apresentou o maior número de empresas que não publicaram o relatório de sustentabilidade foi o de Consumo Cíclico e todas as empresas advêm do segmento da Agropecuária. As empresas do setor de Bens Industriais que não divulgaram as informações são do segmento Construção e Engenharia (01), Máquinas e Serviços (01), Transportes (02) e Serviços Diversos (03). Já o Setor Financeiro e Outros, que se apresentou como o segundo setor com o maior número de empresas, que não publicou o relatório advêm do segmento Serviços Financeiros Diversos (2) e Previdência e Seguros (9).

Vale ressaltar que das 56 que não divulgaram o relatório de sustentabilidade, 14 empresas simplesmente não apresentaram o motivo da não divulgação (Figura 4).

\begin{tabular}{|l|l|l|l|}
\hline \multicolumn{1}{|c|}{ Razão social } & \multicolumn{1}{c|}{ Setor econômico } & \multicolumn{1}{c|}{ Razão social } & \multicolumn{1}{c|}{ Setor econômico } \\
\hline ANIMA & Consumo cíclico & LINX & Tecnologia da informação \\
\hline BR BROKERS & Financeiros e outros & OSX BRASIL & Petróleo, Gás e Biocombustíveis \\
\hline $\begin{array}{l}\text { BR } \\
\text { INSURANCE }\end{array}$ & Financeiros e outros & PETRORIO & Petróleo, Gás e Biocombustíveis \\
\hline CETIP & Financeiros e outros & RODOBENSIMOB & Consumo cíclico \\
\hline ENEVA & Utilidade pública & SMILES & Consumo cíclico \\
\hline IDEIASNET & Tecnologia da informação & SPRINGS & Consumo cíclico \\
\hline KROTON & Consumo cíclico & VIVER & Consumo cíclico \\
\hline
\end{tabular}

Figura 4. Não indicaram o motivo para não publicar relatório de sustentabilidade

Fonte: Elaborado pelos autores (2017)

Atentando para anexo I da Lei $\mathrm{n}^{0} 10.165$ (Brasil, 2000), observa-se que algumas empresas listadas na Figura 4, tais como OSX e Pretorio, são empresas que possuem atividades potencialmente poluidoras e utilizadores de recursos ambientais classificadas como de grau alto.

O que mais chama atenção nessa listagem de empresas é que boa parte delas evidenciam em seus sites corporativos possuírem políticas socioambientais e ainda assim não se posicionam frente a uma exigência da B3. Algumas políticas socioambientais evidenciadas no site corporativo dessas empresas foram: a) programas sociais; b) investem em educação e formação dos colaboradores; c) possuem programas de eficiência energética; e d) otimização de recursos hídricos e gestão dos resíduos sólidos. Nesse cenário, vale destacar as colocações de Giunipero et al. (2012) que explanam que tem que ocorrer uma iniciativa governamental para regularizar e cobrar das empresas, principalmente do novo mercado e de empresas com um nível alto de atividade potencialmente poluidora.

Na próxima subseção, apresenta-se a identificação e análise dos motivos relatados pelas 42 empresas para a não divulgação do relatório de sustentabilidade.

\subsection{Motivos da não divulgação dos relatórios de sustentabilidade}

Do exposto na Figura 5, observa-se que o motivo mais apontado para a não divulgação dos relatórios de sustentabilidade foi o fato de não possuírem políticas socioambientais, com 23 frequências; em segundo lugar, com sete frequências, figurou o motivo de que "precisam melhorar seus processos internos" para poderem divulgar relatórios de sustentabilidade, e o motivo "fatores organizacionais e valores", relacionados ao apoio e comprometimento dos funcionários e dos membros da alta cúpula administrativa. Em seguida, têm o motivo dos custos, com 3 frequências; e por fim a legislação/regulação, com duas frequências. 


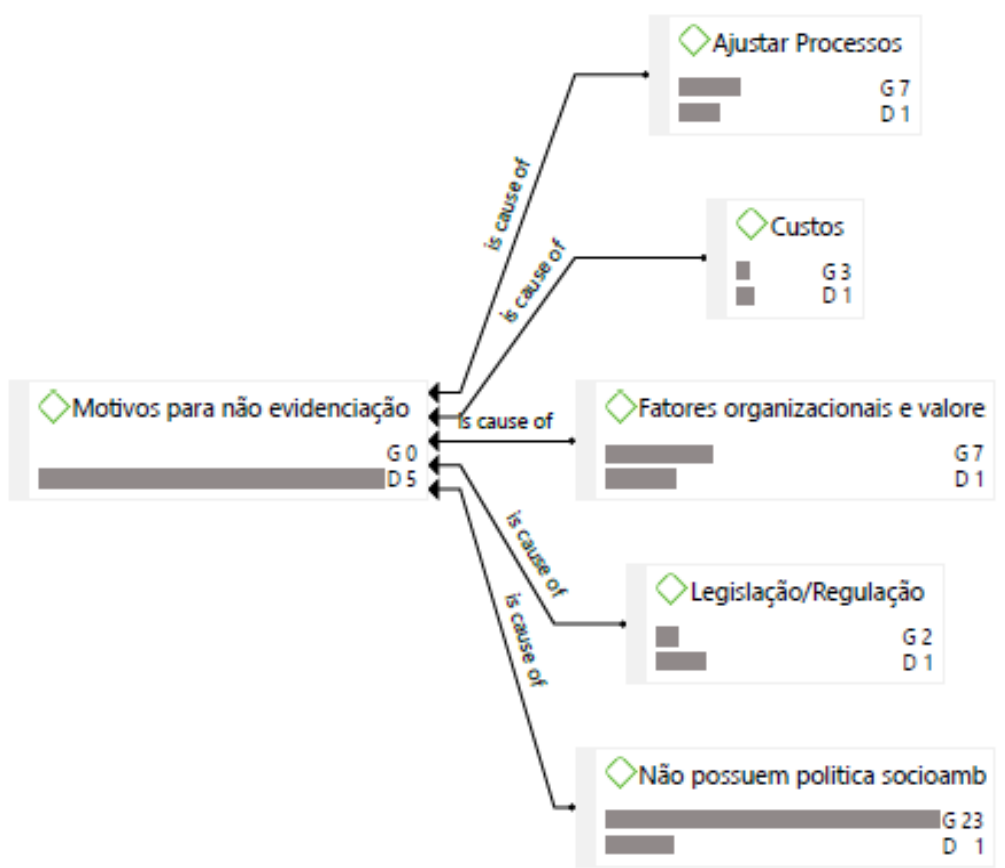

Figura 5. Motivos da não divulgação dos relatórios de sustentabilidade

Fonte: Elaborada pelos autores (2017)

Nota: G - frequência e D - dimensão

Na Figura 6, apresenta-se as 23 empresas que alegaram o motivo de não possuírem políticas socioambientais. E estão distribuídos nos seguintes setores econômicos: (i) Bens Industriais (01); (ii) Consumo Cíclico (10); (iii) Consumo Não Cíclico (01); (iv) Financeiro e Outros (08); (v) Petróleo, Gás e Biocombustíveis (01) e Saúde (02).

De acordo com o anexo I da Lei n0 10.165 (Brasil, 2000), as empresas listadas na Figura 6, como Arezzo CO, CR2, Grendene, Eztec e Lupatech, são empresas que possuem atividades potencialmente poluidoras e utilizadoras de recursos ambientais classificadas como de Grau Médio. O restante das empresas está classificado como de Grau Baixo.

\begin{tabular}{|l|l|l|}
\hline \multicolumn{1}{|c|}{ Razão social } & Setor & \multicolumn{1}{c|}{ Trecho } \\
\hline AIG GROUP & $\begin{array}{l}\text { Financeiro } \\
\text { e outros }\end{array}$ & $\begin{array}{l}\text { [.] Não possui ou divulga Relatório de Sustentabilidade e nem possui política } \\
\text { própria para divulgação das ações socioambientais. Seu posicionamento } \\
\text { quanto ao tema ocorre por meio dos relatórios produzidos tanto pelo seu } \\
\text { controlador (Banco do Brasil) quanto por suas empresas participadas } \\
\text { conforme descrito no item 7.5(b). }\end{array}$ \\
\hline AREZZO CO & $\begin{array}{l}\text { Consumo } \\
\text { cíclico }\end{array}$ & $\begin{array}{l}\text { A companhia não divulga informações sociais e ambientais e não possui } \\
\text { política formal sobre o assunto. A Companhia observa, no entanto, políticas } \\
\text { públicase legislação vigente. }\end{array}$ \\
\hline BR MALLS PAR & $\begin{array}{l}\text { Financeiro } \\
\text { e outros }\end{array}$ & $\begin{array}{l}\text { A companhia observa a legislação socioambiental em sua atuação na } \\
\text { operação e desenvolvimento de shoppings centers, bem como no momento } \\
\text { da contratação de fornecedores, buscando não se associar a empresas que } \\
\text { adotam práticas socioambientais negativas, notoriamente prejudiciais ao meio } \\
\text { ambiente e ilegal. Atualmente, a companhia está em processo de } \\
\text { desenvolvimento de uma Política Socioambiental. }\end{array}$ \\
\hline BR PHARMA & Saúde & $\begin{array}{l}\text { Por ser uma companhia ainda em processo de integração operacional e de } \\
\text { tecnologia da informação, ainda não possuímos um conjunto completo de } \\
\text { ações relacionadas ao impacto das nossas operações no meio ambiente que a } \\
\text { permitam divulgarem um relatório de sustentabilidade ou documento similar } \\
\text { contendo informações sociais e ambientais. }\end{array}$ \\
\hline BR PROPERT & $\begin{array}{l}\text { Financeiro } \\
\text { e outros }\end{array}$ & $\begin{array}{l}\text { Na data deste Formulário, a Companhia não possui uma Política } \\
\text { Socioambiental. }\end{array}$ \\
\hline CR2 & Consumo & \begin{tabular}{l} 
A Companhia não possui políticas socioambientais, bem como não há em sua \\
\hline
\end{tabular} \\
\hline
\end{tabular}

Revista de Gestão Social e Ambiental - RGSA, São Paulo, v. 12, n. 3, p. 58-76, set./dez. 2018. 


\begin{tabular}{|c|c|c|}
\hline & cíclico & rotina a publicação de relatório de sustentabilidade ou documento similar. \\
\hline EZTEC & $\begin{array}{l}\text { Consumo } \\
\text { cíclico }\end{array}$ & $\begin{array}{l}\text { Não aplicável, tendo em vista que a Companhia não divulga informações } \\
\text { socioambientais. }\end{array}$ \\
\hline $\begin{array}{l}\text { GENERALSHOP } \\
\mathrm{P}\end{array}$ & $\begin{array}{l}\text { Financeiro } \\
\text { e outros }\end{array}$ & $\begin{array}{l}\text { A Companhia não divulga o Relatório de Sustentabilidade ou Integrado. } \\
\text { Entretanto, adota determinadas práticas no sentido de sustentabilidade, } \\
\text { conforme relatado em outros itens do formulário. Está buscando desenvolver } \\
\text { políticas socioambientais. }\end{array}$ \\
\hline GRENDENE & $\begin{array}{l}\text { Financeiro } \\
\text { e outros }\end{array}$ & $\begin{array}{l}\text { A Grendene não tem uma política socioambiental, mas divulga as } \\
\text { informações sociais e ambientais que julga relevantes em seu site de } \\
\text { Relações com Investidores, nas Demonstrações Financeiras e no Relatório da } \\
\text { Administração. }\end{array}$ \\
\hline JHSF PART & $\begin{array}{l}\text { Consumo } \\
\text { cíclico }\end{array}$ & $\begin{array}{l}\text { Embora não possua políticas socioambientais formalizadas, a Companhia } \\
\text { adota as melhores práticas de sustentabilidade nos projetos que desenvolve. }\end{array}$ \\
\hline LOCAMERICA & $\begin{array}{l}\text { Consumo } \\
\text { cíclico }\end{array}$ & $\begin{array}{l}\text { A Companhia não aderiu aos padrões internacionais de proteção ambiental e } \\
\text { não publica relatório de sustentabilidade ou documento similar. }\end{array}$ \\
\hline LOG-IN & $\begin{array}{l}\text { Bens } \\
\text { industriais }\end{array}$ & $\begin{array}{l}\text { A Login não possui política socioambiental, entretanto possui política } \\
\text { ambiental para suas principais atividades: navegação e Terminal de Vila } \\
\text { Velha (TVV). }\end{array}$ \\
\hline LUPATECH & $\begin{array}{l}\text { Petróleo, } \\
\text { gás e } \\
\text { biocombus } \\
\text { tíveis }\end{array}$ & $\begin{array}{l}\text { [...]. Não há, até a data de apresentação deste formulário, fatos ou atividades } \\
\text { que justifiquem a elaboração do relatório anual de sustentabilidade. }\end{array}$ \\
\hline $\begin{array}{l}\text { PARCORRETOR } \\
\text { A }\end{array}$ & $\begin{array}{l}\text { Financeiro } \\
\text { e outros }\end{array}$ & $\begin{array}{l}\text { Em } 31 \text { de dezembro de } 2015 \text {, não possuíamos relatório de sustentabilidade e } \\
\text { nem divulgávamos informações ambientais, em razão da natureza de nossos } \\
\text { negócios (prestação de serviços). }\end{array}$ \\
\hline POMIFRUTAS & $\begin{array}{l}\text { Consumo } \\
\text { não cíclico }\end{array}$ & $\begin{array}{l}\text { Não publicamos relatório de sustentabilidade ou similar, por não possuirmos } \\
\text { iniciativas diretamente relacionadas ao tema. }\end{array}$ \\
\hline QUALICORP & Saúde & $\begin{array}{l}\text { Não publicamos relatório de sustentabilidade ou similar, por não possuirmos } \\
\text { iniciativas diretamente relacionadas ao tema. }\end{array}$ \\
\hline ROSSI RESID & $\begin{array}{l}\text { Consumo } \\
\text { cíclico }\end{array}$ & $\begin{array}{l}\text { Item não é aplicável, pois a Companhia não divulga informações } \\
\text { socioambientais ao mercado. }\end{array}$ \\
\hline SAO CARLOS & $\begin{array}{l}\text { Financeiro } \\
\text { e outros }\end{array}$ & $\begin{array}{l}\text { [...]. A Companhia atualmente não publica um relatório de sustentabilidade } \\
\text { ou similar, mas publica um relatório anual que contém capítulo específico } \\
\text { sobre este tema, notadamente no que se refere ao aspecto ambiental. [...] } \\
\text { Atualmente, a companhia está em processo de desenvolvimento de uma } \\
\text { Política Socioambiental. }\end{array}$ \\
\hline SER EDUCA & $\begin{array}{l}\text { Consumo } \\
\text { cíclico }\end{array}$ & $\begin{array}{l}{[\ldots] \text { apesar de adotar práticas internas de sustentabilidade e de relacionamento }} \\
{[\ldots] \text {, ainda não possui um relatório completo de sustentabilidade. }}\end{array}$ \\
\hline TARPON INV & $\begin{array}{l}\text { Financeiro } \\
\text { e outros }\end{array}$ & $\begin{array}{l}\text { [...] não publica o Relatório de Sustentabilidade em razão de entender que as } \\
\text { práticas adotadas pela Companhia, nesse sentido, não podem ser } \\
\text { caracterizadas como relações de longo prazo relevantes. }\end{array}$ \\
\hline TECHNOS & $\begin{array}{l}\text { Consumo } \\
\text { cíclico }\end{array}$ & $\begin{array}{l}\text { A Technos não publica relatório de sustentabilidade ou similar, visto que as } \\
\text { atividades desenvolvidas atualmente não possuem impactos ambientais } \\
\text { significativos [...]. }\end{array}$ \\
\hline TIME FOR FUN & $\begin{array}{l}\text { Consumo } \\
\text { cíclico }\end{array}$ & $\begin{array}{l}\text { [...]. A T4F não possui atualmente um conjunto completo de ações } \\
\text { relacionadas ao impacto de suas operações no meio ambiente que justifique } \\
\text { divulgar relatório de sustentabilidade ou documento similar. }\end{array}$ \\
\hline TRISUL & $\begin{array}{l}\text { Consumo } \\
\text { cíclico }\end{array}$ & Não, a Trisul não publica relatório de sustentabilidade ou similar [...]. \\
\hline
\end{tabular}

Figura 6. Motivo: não possuírem políticas socioambientais

Fonte: Elaborada pelos autores (2017)

$\mathrm{Na}$ Figura 7, constam as sete empresas que alegaram o motivo de que precisam melhorar seus processos internos. Atentando para o anexo I da Lei n0 10.165 (Brasil, 2000), vê-se que algumas das empresas listadas na Figura 7, como Contax, CSU Cardsyst e Somos Educa, são empresas que possuem atividades potencialmente poluidoras e utilizadores de recursos ambientais classificadas como de grau baixo. O restante das empresas está classificado como de Grau Médio. Dentre os tipos de melhorias internas foram citados: adequação da estrutura organizacional, desenvolvimento de conscientização sustentável, intensificação de treinamentos, instituição de 
auditorias, modernização de equipamentos e etc. Cabe salientar que as empresas apontam em seus sites corporativos possuírem políticas de sustentabilidade, e, apesar disso, não publicam o relatório socioambiental no site da B3, com exceção da Somos Educa que não evidenciou em seu site adotar qualquer política socioambiental.

\begin{tabular}{|c|c|c|}
\hline Razão social & $\begin{array}{c}\text { Setor } \\
\text { econômico }\end{array}$ & Trecho \\
\hline Contax & $\begin{array}{l}\text { Bens } \\
\text { Industriais }\end{array}$ & $\begin{array}{l}\text { A Companhia tem avaliado suas iniciativas nas áreas social, ambiental e de } \\
\text { governança corporativa com vistas a construir no médio prazo um histórico } \\
\text { consistente de indicadores que permitam o reporte sistematizado dessas } \\
\text { informações bem como o aprimoramento contínuo dessas iniciativas. }\end{array}$ \\
\hline CSU Cardsyst & $\begin{array}{l}\text { Bens } \\
\text { Industriais }\end{array}$ & $\begin{array}{l}\text { A Companhia [...] está em fase de implementação de diagnóstico e avaliações } \\
\text { periódicas para medir o sucesso de seus esforços sustentáveis que visam } \\
\text { reduzir custos econômicos, impactos ambientais e melhorar sua eficiência } \\
\text { produtiva. [...] }\end{array}$ \\
\hline Cyrela Realt & $\begin{array}{l}\text { Consumo } \\
\text { não cíclico }\end{array}$ & $\begin{array}{l}\text { A Companhia não publica Relatório de Sustentabilidade, pois ainda não } \\
\text { possui processos e práticas consolidadas nacionalmente, seja por meio das } \\
\text { suas unidades de negócio ou de suas JointVentures[...]. }\end{array}$ \\
\hline Direcional & $\begin{array}{l}\text { Consumo } \\
\text { não cíclico }\end{array}$ & $\begin{array}{l}\text { [...] Gostaríamos de frisar que apesar de adotarmos práticas de } \\
\text { sustentabilidade social e ambiental em nossos canteiros de obras, escritórios e } \\
\text { nas regiões onde atuamos ainda não publicamos Relatório de Sustentabilidade. } \\
\text { Entretanto, estamos nos estruturando para atender tal prática de governança, } \\
\text { pois a Sustentabilidade é um dos pilares de nosso negócio. }\end{array}$ \\
\hline Lojas Marisa & $\begin{array}{l}\text { Consumo } \\
\text { cíclico }\end{array}$ & $\begin{array}{l}\text { A Marisa Lojas S.A. ("Marisa"), possui diversas iniciativas internas e externas } \\
\text { de responsabilidade social e ambiental. Contudo, a Companhia não consolida } \\
\text { suas ações em relatório específico para divulgação, qual seja, o Relatório de } \\
\text { Sustentabilidade. A Marisa compreende a relevância deste tema e estuda o } \\
\text { desenvolvimento de equipe dedicada ao assunto para os próximos períodos e, } \\
\text { com isso, passará a elaborar o citado relatório. }\end{array}$ \\
\hline MILLS & $\begin{array}{l}\text { Bens } \\
\text { Industriais }\end{array}$ & $\begin{array}{l}\text { A Companhia está em fase de estruturação dos processos, visando atuar de } \\
\text { forma sustentável. A Companhia não publica relatório de sustentabilidade ou } \\
\text { similar. Por considerar importante a ampliação da transparência sobre o } \\
\text { assunto sustentabilidade, a Companhia está analisando a formalização de um } \\
\text { processo de análise (diagnóstico) e plano de ação para melhorar suas práticas } \\
\text { de sustentabilidade. }\end{array}$ \\
\hline Somos Educa & $\begin{array}{l}\text { Consumo } \\
\text { Cíclico }\end{array}$ & $\begin{array}{l}\text { [...] Atualmente, a Companhia possui um grupo de estudos interno focado na } \\
\text { elaboração de (i) mecanismos de monitoramento de indicadores ambientais e } \\
\text { políticas sociais que envolvam todas as suas sedes, filiais e sociedades } \\
\text { controladas. }\end{array}$ \\
\hline
\end{tabular}

Figura 7. Motivo: precisam melhorar os seus processos internos

Fonte: Elaborada pelos autores (2017)

Do exposto na Figura 8, observa-se que sete empresas alegaram o motivo "fatores organizacionais e os valores da companhia". Analisando o estatuto social dessas empresas, verificou-se a existência de projetos de cunho social, porém não é evidenciada nenhuma ação ou projeto de cunho ambiental como: (i) uso de ecodesign; (ii) eficiência energética; (iii) otimização de recursos hídricos; (iv) tratamento de águas e efluentes; (v) gestão de resíduos sólidos e etc.

\begin{tabular}{|c|c|c|}
\hline Razão social & $\begin{array}{c}\text { Setor } \\
\text { econômico }\end{array}$ & Trecho \\
\hline Gafisa & $\begin{array}{l}\text { Consumo } \\
\text { cíclico }\end{array}$ & $\begin{array}{l}\text { [...]. A administração da companhia está avaliando a implementação de um } \\
\text { projeto para futura elaboração e divulgação deste relatório. }\end{array}$ \\
\hline Lopes Brasil & $\begin{array}{l}\text { Financeiro e } \\
\text { outros }\end{array}$ & $\begin{array}{l}\text { [...].a LPS Brasil informa que não publica Relatório de Sustentabilidade ou } \\
\text { documento similar. A Companhia informa também que está avaliando políticas } \\
\text { internas e propostas para divulgá-lo futuramente. }\end{array}$ \\
\hline Metalfrio & $\begin{array}{l}\text { Bens } \\
\text { industriais }\end{array}$ & $\begin{array}{l}\text { A Companhia possui política interna ambiental, que norteia toda a linha de } \\
\text { atuação e gerenciamento da Companhia, assegurando sua difusão, compreensão } \\
\text { e cumprimento em todos os níveis da organização. Entretanto, esta política é }\end{array}$ \\
\hline
\end{tabular}

Revista de Gestão Social e Ambiental - RGSA, São Paulo, v. 12, n. 3, p. 58-76, set./dez. 2018. 


\begin{tabular}{|c|c|c|}
\hline & & divulgada somente a nível interno. [...]. \\
\hline Tegma & $\begin{array}{l}\text { Bens } \\
\text { industriais }\end{array}$ & $\begin{array}{l}\text { [...] apesar de adotar práticas de sustentabilidade socioambientais, envidar os } \\
\text { maiores esforços para a proteção do meio ambiente e dispor de práticas } \\
\text { corporativas voltadas à sustentabilidade, ainda não publica suas ações em um } \\
\text { relatório específico para divulgação [...]. }\end{array}$ \\
\hline Unicasa & $\begin{array}{l}\text { Consumo } \\
\text { cíclico }\end{array}$ & $\begin{array}{l}\text { [...] Estamos analisando todo o contexto que envolve a sustentabilidade e a sua } \\
\text { geração de valor. A Direção da Unicasa está comprometida com o } \\
\text { desenvolvimento sustentável e busca desenvolver e estruturar um relatório de } \\
\text { sustentabilidade, demonstrando os valores da sustentabilidade corporativa a seus } \\
\text { investidores e ao mercado em geral, que será publicado no futuro próximo. }\end{array}$ \\
\hline $\begin{array}{l}\text { V-AGRO } \\
\text { TERRA } \\
\text { SANTA } \\
\text { AGRO }\end{array}$ & $\begin{array}{l}\text { Consumo } \\
\text { não cíclico }\end{array}$ & $\begin{array}{l}\text { [...] Entendemos que a sustentabilidade deve estar alinhada, antes de qualquer } \\
\text { ação externa, aos princípios e diretrizes adotados pela própria Companhia }[\ldots\} \text {... }\end{array}$ \\
\hline VALID & $\begin{array}{l}\text { Bens } \\
\text { industriais }\end{array}$ & $\begin{array}{l}\text { A Companhia informa que não publica Relatório de Sustentabilidade ou similar } \\
\text { desde 2012, porém cabe ressaltar que adota as práticas socioambiental descritas. }\end{array}$ \\
\hline
\end{tabular}

Figura 8. Motivo: fatores organizacionais e valores da companhia

Fonte: Elaborada pelos autores (2017)

Young et al. (2013), Caniato et al. (2012) e Giunipero et al. (2012) explanaram como fatores organizacionais e valores da companhia para não evidenciação de informações socioambientais: (i) falta de apoio e comprometimento da alta cúpula administrativa; (ii) implementar políticas e desenvolver uma cultura organizacional voltada a práticas ambientais e incentivar os funcionários a adotar e desenvolver a cultura ambiental.

Do exposto na Figura 9, observa-se que apenas três empresas alegaram o motivo de custos para a não publicação do relatório de sustentabilidade. Atentando para o exposto no anexo I da Lei $\mathrm{n}^{0} 13.361$, essas empresas possuem atividades potencialmente poluidoras.

\begin{tabular}{|c|c|c|}
\hline Razão social & \begin{tabular}{|c|}
$\begin{array}{c}\text { Setor } \\
\text { econômico }\end{array}$ \\
\end{tabular} & Trecho \\
\hline HELBOR & $\begin{array}{l}\text { Consumo } \\
\text { cíclico }\end{array}$ & $\begin{array}{l}\text { [...] não publica Relatório de Sustentabilidade ou documento similar, por entender que } \\
\text { o modelo de negócios da Companhia, que é a contratação de construtoras para } \\
\text { executar as obras, muitas vezes inviabiliza o adequado controle das práticas } \\
\text { sustentáveis em suas atividades. }\end{array}$ \\
\hline IMC S/A & $\begin{array}{l}\text { Consumo } \\
\text { cíclico }\end{array}$ & $\begin{array}{l}\text { A Companhia informa que atualmente estuda formas de viabilizar a implantação do } \\
\text { Relatório de Sustentabilidade, considerando os recursos orçamentários e estruturais } \\
\text { que a elaboração deste Relatório requer, para que sua divulgação seja ampla e } \\
\text { coordenada com as melhores práticas de governança, seguindo as tendências mais } \\
\text { consolidadas de Relatório constantes no Mercado em geral [...]. }\end{array}$ \\
\hline $\begin{array}{l}\text { PDG } \\
\text { REALT }\end{array}$ & $\begin{array}{l}\text { Consumo } \\
\text { cíclico }\end{array}$ & $\begin{array}{l}\text { A PDG não publica o Relatório de Sustentabilidade ou documento semelhante por } \\
\text { representar um custo relevante para a Companhia. }\end{array}$ \\
\hline
\end{tabular}

Figura 9. Motivo: custos

Fonte: Elaborada pelos autores (2017)

Walker et al. (2008) relatam que o custo é uma barreira para a sustentabilidade porque precisa de alto investimento inicial e é necessária a contratação de profissionais qualificados para treinar e implantar a filosofia sustentável (Luthra et al., 2011). Percebe-se que as empresas utilizam as palavras "viabilizar", "inviabilizar" e "custo relevante" para demonstrar essa dificuldade para as empresas implementarem a divulgação do relatório de sustentabilidade.

Já na Figura 10, são expostas as duas empresas que alegaram o motivo da legislação e regulamentação ambiental. E estão distribuídos nos seguintes setores econômicos: Consumo Cíclico e Materiais básicos. De acordo com o anexo I da Lei $\mathrm{n}^{0} 10.165$ (Brasil, 2000), as empresas listadas na Figura 10, a LE LIS Blanc é uma empresa que possui atividade potencialmente poluidora e utilizadores de recursos ambientais classificadas como de grau Baixo, mas a CCX Carvão é uma empresa de grau Alto. 


\begin{tabular}{|l|l|l|}
\hline Razão social & \multicolumn{1}{|c|}{$\begin{array}{c}\text { Setor } \\
\text { econômico }\end{array}$} & \multicolumn{1}{c|}{ Trecho } \\
\hline LE LIS Blanc & $\begin{array}{l}\text { Consumo } \\
\text { cíclico }\end{array}$ & $\begin{array}{l}\text { A Companhia não elabora relatório de sustentabilidade, tendo em vista que não } \\
\text { há exigência legal nesse sentido. }\end{array}$ \\
\hline CCX Carvao & $\begin{array}{l}\text { Materiais } \\
\text { básicos }\end{array}$ & $\begin{array}{l}{[\ldots] \text { não divulga informações sociais e ambientais, mas como suas operações e }} \\
\text { ativos estão situados na Colômbia, a Cia segue rigorosamente as legislações } \\
\text { socioambientais aplicáveis e até então não houve qualquer reclamação formal } \\
\text { por parte das autoridades locais. }\end{array}$ \\
\hline
\end{tabular}

Figura 10. Motivo: legislação e regulamentação governamental

Fonte: Elaborada pelos autores (2017)

Wu, Ding e Chen (2012) discorrem sobre a necessidade de o governo adotar ações que possam providenciar as condições adequadas para que as empresas possam evidenciar esses relatórios. Essa cobrança tem que ocorrer, pois algumas empresas, tal como a CCX, publicam relatórios socioambientais na Colômbia, porém as suas operações no Brasil não são evidenciadas.

\section{CONSIDERAÇÕES FINAIS}

A adaptação das empresas em relação às práticas socioambientais exigidas pelos diferentes grupos sociais tem acarretado reflexos na gestão e também no modo como informam sua interação com o meio ambiente. Nesse sentido, percebe-se que se tem tornado constante a busca por maior evidenciação por parte das empresas, no que se refere às informações de caráter socioambiental. Desta forma, como o objetivo de identificar os motivos da não evidenciação de relatórios socioambientais pelas companhias listadas no segmento Novo Mercado da B3 procedeu-se análise dos motivos apontados no relatório "Relate ou Explique".

Em relação ao objetivo específico 1, os achados levam a considerar que as empresas do Novo Mercado da B3 - que é um mercado destinado a negociações de ações de empresas com um padrão altamente diferenciado de $\mathrm{GC}$, além da adoção de uma política de disclosure mais abrangente e transparente - não estão preocupadas em buscar a tão almejada "diferenciação" mercadológica, já que, de um universo de 126 empresas, 56 não evidenciaram essa preocupação no site da B3.

Quanto aos motivos da não divulgação dos relatórios de sustentabilidade (objetivo específico 2) dos onze fatores identificados na literatura, foram apontados quatro. São eles: (i) precisam melhorar os seus processos internos (7 empresas); (ii) fatores organizacionais e valores (7 empresas); (iiii) custos (3 empresas); e (iv) legislação e regulamentação ambiental (2 empresas). E o quinto motivo - (V) não possuem políticas socioambientais (23 empresas) - emergiu da coleta de dados e foi o mais apontado pelas empresas.

Já em relação ao objetivo específico 3, atentando para o Anexo I da Lei $n^{0} 10.165$ (Brasil, 2000), as empresas objeto de estudo estão classificadas de acordo com atividades potencialmente poluidoras e utilizadores de recursos ambientais. Também chamou a atenção nos achados dessa pesquisa que somente uma empresa não evidenciou em seu site práticas socioambientais. As demais empresas evidenciaram algum tipo de prática mesmo não publicando o relatório de sustentabilidade.

Portanto, conclui-se que, o nível de divulgação de informações socioambientais por parte das empresas do Novo Mercado da B3 precisa ser melhorado, para que a governança corporativa e responsabilidade social corporativa não sejam apenas discursos teóricos.

Cabe destacar a contribuição acadêmica da pesquisa, em que emergiu um novo motivo para não divulgação dos relatórios de sustentabilidade - não possuir políticas socioambientais. Para futuros estudos, recomenda-se a análise dessa forma de comunicação das organizações para com os seus diversos públicos quanto às mensagens que tentam transmitir sobre suas ações de responsabilidade socioambiental. 


\section{REFERÊNCIAS}

Adriana, B. (2009) Environmental supply chain management in tourism: the case of large tour operators. Journal of Cleaner Production, 17(16), 385-1392.

Ageron, B., Gunasekaran, A., \& Spalanzani, A. (2012). Sustainable supply management: An empirical study. International Journal of Production Economics, 140(1), 168-182.

Aguilera, R. V., Williams, C. A., Conley, J. M., \& Rupp, D. E. (2006). Corporate governance and social responsibility: a comparative analysis of the UK and the US. Corporate Governance: An International Review, 14, 147-158.

Aras, G., \& Crowther, D. (2008). Governance and sustainability: an investigation into the relationship between corporate governance and corporate sustainability. Management Decision, 46, 433-448.

Arimura, T. H., Darnall, N., \& Katayama, H. (2011). Is ISO 14001 a gateway to more advanced voluntary action? The case of green supply chain management. Journal of Environmental Economics and Management, 61(2), 170-182.

Arora, P., \& Dharwadkar, R. (2011). Corporate governance and corporate social responsibility (CSR): the moderating roles of attainment discrepancy and organization slack. Corporate Governance: An International Review, 19(2), 136-152.

Bardin, L. (2011). Análise de conteúdo. (3. ed.) Lisboa: Edições, 70.

Baumgartner, R. J. (2014). Managing corporate sustainability and CSR: a conceptual framework combining values, strategies and instruments contributing to sustainable development. Corporate Social Responsibility Environmental Management, 21(5), 258-271.

Beltratti, A. (2005). The complementarity between corporate governance and corporate social responsibility. The Geneva Paper son Risk and Insurance Issues and Practice, 30(3), 373-386.

Bhimani, A., \& Soonawalla, K. (2005). From conformance to performance: The corporate responsibilities continuum. Journal of A ccounting and Public Policy, 24(3), 165-174.

Bjorklund, M. (2011). Influence from the business environment on environmental purchasingDrivers and hinders of purchasing green transportation services. Journal of Purchasing and Supply Management, 17(1), 11-22.

BM\&FBovespa. (2016). Relatório de Sustentabilidade ou Integrado. Recuperado em 2 nov.2016, de: $<$ http://www.bmfbovespa.com.br/cias-listadas/consultas/relatorio-de sustentabilidade.aspx?idioma $=$ pt-br $>$.

Braga, J. P., Oliveira, J. R. S., Salotti, B. M. (2009). Determinantes do nível de divulgação ambiental nas demonstrações contábeis de empresas brasileiras. Revista de Contabilidade da Ufba, 3(3), 81-95.

Caniato, F., Caridi, M., Crippa, L., \& Morreto, A. (2012). Environmental sustainability in fashion supply chains: an exploratory case based research. International Journal of Production Economics, 135(2), 659-670.

Chiou, T., Chan, H., Lettice, F., \& Chung, S. (2011). The influence of greening the suppliers and green innovation on environmental performance and competitive advantage in Taiwan. Transportation Research Part E: Logistics and Transportation Review, 47(6), 822-836.

Cormier, D., \& Magnan, M. (2013). The economic relevance of environmental disclosure and its impact on corporate legitimacy: an empirical investigation. Business Strategy and the Environment, 24(6), 431-450. 
Crespin-Mazet, F., \& Dontenwill, E. (2012). Sustainable procurement: building legitimacy in the supply network. Journal of Purchasing and Supply Management, 18(4), 207-217.

De Moraes, C. M. et al. (2017). Produção acadêmica brasileira no contexto dos relatórios de sustentabilidade: uma análise bibliométrica. Revista de Gestão, Finanças e Contabilidade, 7(2), 197.

De Oliveira, O. J., \& Serrab, J. R. (2010). Benefícios e dificuldades da gestão ambiental com base na ISO 14001 em empresas industriais de São Paulo. Revista Produção, 20, 429-438.

Degenhart, L. et al. (2016). Avaliação do grau de evidenciação dos impactos ambientais em relatórios de sustentabilidade e relatórios anuais de empresas brasileiras. Revista Metropolitana de Sustentabilidade, 6(1), 81 .

Dunlop, A. (1998). Corporate governance and control. Kogan Page Publishers.

Elkington, J. (2006). Governance for sustainability. Corporate Governance: an International Review, 14(6), 522-529.

Freeman, R. E. (1984). Strategic management: a stakeholder approach. Boston: Pitman.

Giunipero, L. C., Hooker, R. E., \& Denslow, D. (2012). Purchasing and supply management sustainability: Drivers and barriers. Journal of Purchasing and Supply Management, 18(4), 258269.

Hancock, J. (2005). Investing in corporate social responsibility: a guide to bestpractice, business planning \& the UK's leading companies. Kogan Page Publishers.

Harjoto, M. A., \& Jo, H. (2011). Corporate governance and CSR nexus. Journal of Business Ethics, $100(1), 45-67$.

Hendriksen, E. S., \& Van Breda, M. F. (1999). Teoria da contabilidade. São Paulo: Atlas.

Ho, C. (2005). Corporate governance and corporate competitiveness: an international analysis. Corporate Governance: an International Review, 13(2), 211-253.

Ilg, M. (2007). An essay on social responsibility and the limits of the corporate form: A perspective on environmental protection. Journal of environmental Law and Practice, 17(2), 115, 2007.

Jamali, D., Safieddine, A. M., \& Rabbath, M. (2008). Corporate governance and corporate social responsibilitysynergiesandinterrelationships. Corporate Governance: an International Review, 16(5), 443-459.

Jo, H., Harjoto, M. A. (2012). The causal effect of corporate governance on corporate social responsibility. Journal of business ethics, 106(1), 53-72.

Khan, A., Muttakin, M. B., \& Siddiqui, J. (2013). Corporate governance and corporate social responsibility disclosures: evidence from an emerging economy. Journal of business ethics, 114(2), 207-223.

Knox, S., \& Maklan, S. (2004). Corporate social responsibility: Moving beyond investment towards measuring outcomes. European Management Journal, 22, 508-516.

Lane, C. (2003). Changes in the corporate governance of german corporations: convergence on the anglo-american model? Competition and Change, England, 7(2-3), 79-100.

Luo, Y. (2006). Global dimensions of corporate governance. Malden: Blackwell Publishing.

Luthra, S. et al. (2011). Barriers to implement green supply chain management in automobile industry using interpretive structural modeling technique: an Indian perspective. Journal of Industrial Engineeringand Management, 4(2), 231-257. 
Marsiglia, E., \& Falautano, I. (2005). Corporate social responsibility and sustainability challenges for a Bancassurance Company. The Geneva Paperson Riskand Insurance Issuesand Practice, 30(3), 485-497.

Mathiyazhagan, K. et al. (2013). An ISM approach for the barrier analysis in implementing green supply chain management. Journal of Cleaner Production, 47, 283-297.

Monteiro, P. R. A., Ferreira, A. C. de S. (2007). A evidenciação da informação ambiental nos relatórios contábeis: um estudo comparativo com o modelo do Isar/Unctad. Revista de Gestão Social e Ambiental, 1(1), 82-101.

Muduli, K., Govidan, K., Barve, A., \& Geng, J. (2013). Barriers to green supply chain management in Indian mining industries: a graph theoretic approach. Journal of Cleaner Production, 47, 335344.

Page, J.-P. (2005). Corporate governance and value creation. Research Foundation Publications, 2005(1), 77. Recuperado em: 16 dez.2017, de:

$<$ https://www.cfainstitute.org/learning/products/publications/rf/Pages/rf.v2005.n1.3930.aspx>.

Pajunen, N., Watkins, G., Wierink, M., \& Heiskanen, K. (2012). Drivers and barriers of effective industrial material use. Minerals Engineering, 29, 39-46.

Patton, M. (2012). Qualitative research and evaluation methods. (3. ed.) Thousand Oaks: Sage.

Perrini, F., Pogutz, S., \& Tencati, A. (2006). Corporate social responsibility in Italy: state of the art. Journal of Business Strategies, 23(1), 65.

Perron, G. M. (2005). Barriers to environmental performance improvements in Canadian SMEs. London: Kogan Page Publishers.

Rodrigue, M. (2014). Contrasting realities: corporate environmental disclosure and stakeholderreleased information. Accounting, Auditing \& Accountability Journal, 27(1), 119-149.

Rover, S., Tomazzia, E. C., Murcia, F. D., \& Borba, J. A. (2012). Explicações para a divulgação voluntária ambiental no Brasil utilizando a análise de regressão em painel. Revista de Administração, São Paulo, 47(2), 217-230.

Rover, S. et al. (2008). Divulgação de informações ambientais nas demonstrações contábeis: um estudo exploratório sobre o disclosure das empresas brasileiras pertencentes a setores de alto impacto ambiental. Revista de Contabilidade e Organizações, 2(3), 53.

Sacconi, L. (2012). Corporate social responsibility and corporate governance - working papers. EconomEtica, Centro interuniversitario per l'etica economica e la responsabilità sociale d'impresa, 38. Recuperado em: 16 dez.2017, de: $<$ http://www.econometica.it/ wp/wp38.pdf $>$.

Schmidt, R. H., \& Tyrell, M. (1997). Financial Systems, Corporate Finance and Corporate Governance, European Financial Management, 3(3), 333-361.

Simpson, D. (2012). Institutional pressure and waste reduction: the role of investments in waste reduction resources. International Journal of Production Economics, 139(1), 330-339.

Strauss, A., \& Corbin. (2008). Pesquisa qualitativa: técnicas e procedimentos para o desenvolvimento da teoria fundamentada. (2. ed.) Porto Alegre: Campus.

Tate, W. L., Dooley, K. J., \& Ellram, L. M. (2011). Transaction cost and institutional drivers of supplier adoption of environmental practices. Journal of Business Logistics, 32(1), 6-16.

Tirole, J. (2001). Corporate governance. Econometrica, England, 69(1), 1-35.

Tsoulfas, G. T., \& Pappis, C. P. (2008). A model for supply chains environmental performance analysis and decision making. Journal of Cleaner Production, 16(15), 1647-57. 
Van Den Berghe, L., \& Louche, C. (2005). The link between corporate governance and corporate social responsibility in insurance. The Geneva Papers on Risk and Insurance Issues and Practice, 30(3), 425-442.

Walker, H., Di Sisto, L., \& Mcbain, D. (2008). Drivers and barriers to environmental supply chain management practices: Lessons from the public and private sectors. Journal of purchasing and supply management, 14(1), 69-85.

Wolfslehner, B., \& Vacik, H. (2008). Evaluating sustainable forest management strategies with the analytic network process in a pressure-state-response framework. Journal of Environmental Management, 88(1), 1-10.

Wu, Guo-Ciang, Ding, Jyh-Hong, \& Chen, Ping-Shun. (2012). The effects of GSCM drivers and institutional pressures on GSCM practices in Taiwan's textile and apparel industry. International Journal of Production Economics, 135(2) 618-636.

Yongan, Z., \& Menghan, L. (2011). Research on Green Supply Chain Design for Automotive Industry Based on Green Scor Model. In: 2011 International Conference on Information Management, Innovation Management and Industrial Engineering. Ieee.

Zhang, B., Bi, J., Liu, B. (2009). Drivers and barriers to engage enterprises in environmental management initiatives in Suzhou Industrial Park, China. Frontiers of Environmental Science \& Engineering in China, 3(2), 210-220.

Zhu, Q., Geng, Y., Sarkis, J., \& Lai, K. (2011). Evaluating green supply chain management among Chinese manufacturers from the ecological modernization perspective. Transportation Research Part E: Logistics and Transportation Review, 47(6), 808-821.

Zhu, Q., \& Geng, Y. (2013). Drivers and barriers of extended supply chain practices for energy saving and emission reduction among Chinese manufacturers. Journal of Cleaner Production, 40, $6-12$.

Data da submissão: 28/12/2017

Data de aceite: $13 / 08 / 2018$ 